\title{
Scrapie: a review of its relation to human disease and ageing
}

\author{
E. J. FIELD \\ From the Multiple Sclerosis Research Unit, Royal Victoria Infirmary, Queen Victoria Road, \\ Newcastle upon Tyne NE1 4LP
}

\begin{abstract}
Historical introduction
Scrapie is a naturally occurring disease of sheep which has been recognized in England for nearly 250 years (McGowan, 1914). Indeed as early as 1755 the farmers of Boston (Lincs.) petitioned the House of Commons on account of the economic losses it caused, and sought that 'distempered' animals be restrained from mixing with healthy ones (Palmer, 1959). On the Continent, the disease (under a variety of names-'la tremblante', 'Prurigo lombaire', 'maladie chancelante', 'nevraxite enzootique du mouton', 'Zitternkrankheit', 'Traberkrankheit' (trotting disease), 'Grubberkrankheit' (nibbling disease), 'Reiberkrankheit' (rubbing disease)) was also rampant. Stockman (1913) has reviewed the contentious points in the history of the disease and records the first use of the term scrapie in 1853 . It is commonly said to have been imported into this country with merino sheep from Spain, but isolated outbreaks have occurred in recent times (Palmer, 1959), e.g. in North America and Australia (Bull and Murnane, 1958) and even the remote Himalayan foothills are not immune, though the disease there seems to have been recognized for less than a quarter of a century (Zlotnik and Katiyar, 1961). From the outset, observations in the field posed the question of the relative parts played by inheritance (breed) and infection, and this remains a focal point of interest to the present day. Modern interest in scrapie has been intensified since 1954, when Sigurdsson delivered three lectures in the University of London in which he drew attention to certain naturally occurring diseases of sheep in Iceland which could, however, be passaged experimentally. Among these was the Icelandic disease called 'rida' (meaning 'trembling' and 'maedi' meaning 'breathlessness'). Rida appears to be identical with scrapie. Sigurdsson tentatively suggested three
\end{abstract}

Received 16 September 1975. characteristics of this group of infections which he labelled 'slow' infections.

(a) A very long initial period of latency to be reckoned in months or even years (and now known to extend over one-quarter or even one-third of an animal's natural lifetime).

(b) A regular protracted course once clinical signs had appeared leading to serious disease or death.

(c) Limitation of infection to a single host species with anatomical lesions only in a single organ or tissue system.

Sigurdsson's criteria have, of course, been modified over the years as new facts have come to light, especially with regard to limitation to a single species. However, the number of diseases for which a 'slow virus' aetiology has been postulated has multiplied greatly, and at a symposium devoted to 'Slow, Latent, and Temperate Virus Infections' organized by Drs Gajdusek, Gibbs, and Alpers at Bethesda in December 1955, no fewer than 10 groups of virus infections in man of possible 'slow' type were listed and no less than 21 in animals. Indeed, in recent years perhaps only 'autoimmune disease' has been capable of giving so much verbal satisfaction as 'slow virus infection'. It may be noted that the enlargement of the 'slow' group has included such diseases as rabies. While it is undoubtedly true that rabies virus may lie dormant in the tissues for prolonged periods (perhaps up to 2 years), when it does produce disease it is of a fulminating character quite different from that visualized by Sigurdsson. In the writer's opinion, we should in the present state of our knowledge exclude such conditions and distinguish 'latent' from 'slow' infective agents. It may be noted, too, that Sigurdsson referred to 'slow infections' and not to slow viruses. It is now clear that certain banal viruses, notably measles, may under certain conditions act as 'slow' agents (for example in the 
production of subacute sclerosing panencephalitis (SSPE) and, though this is very much more doubtful, multiple sclerosis (Field, 1975)).

Scrapie itself has become the paradigm of 'slow' infections, especially since the establishment of the disease in mice (Chandler, 1961) and rats (Chandler and Fisher, 1963) has so greatly facilitated its study. As such, it poses fundamental problems in molecular biology, even perhaps presenting a challenge to the Watson-Crick dogma (Lancet, 1967) that nucleic acids alone are capable of carrying instructional information. Pirie (1966) has indeed considered the possibility that substances other than nucleic acid (e.g. a polysaccharide) may transmit, while Field (1967b) has postulated, with reference to scrapie, that a small fragment comprising a few aggregated polysaccharide chains, if transplanted into another cell, might initiate a seeding out process in the cytoplasm and so create the illusion of self-replication. Pattison and Jones (1968b) have pointed out that the fact that scrapie can be passed indefinitely through animals in series does not necessarily mean classical replication of the virus; an interesting suggestion commented upon in Nature (1967). They claimed that scrapie may on rare occasion result from the inoculation of (apparently) normal brain tissue, and suggested that the agent was present in an inhibited form in normal tissue and in released form in scrapie brain. Such an unmasking would, they claimed, provide an alternative explanation to selfreplication. Such problems have clear relation to the membrane hypothesis of Gibbons and Hunter considered in some detail below.

\section{Clinical features of scrapie}

Natural scrapie is almost entirely limited to sheep, very seldom affecting animals under 2 years of age, but may come on over 5 years. It has been recorded in the goat under natural conditions (Chelle, 1942), though the disease may readily be established in this species by intracerebral inoculation (Pattison, 1957) and a detailed histological study has been made by Hadlow (1961). In sheep the onset is generally insidious with slight behavioural changes such as nervousness and excitability. Rubbing or scratching over the lumbar region may elicit a rubbing reflex. Neurological signs intensify at the same time as the animal shows a tendency to rub itself against a fence or telegraph pole so that areas of fleece, especially over the flank or rump, are lost (Fig. 1). Tremor and incoordination, especially on sudden change of direction, increase, teeth grinding is sometimes marked, and the animal, if hurried, may show a high stepping gait ('cuddy trot').
Some animals show thirst. The course may be over a few months or rapid over a few weeks, and not a few die suddenly. General weakness follows and inability to rise leads to death, though Stockman (1926) believes that occasionally recovery may take place. Excellent detailed clinical descriptions of the disease have been given by many authors (Stockman, 1913; Wilson et al, 1950; Stamp, 1956, and many others).

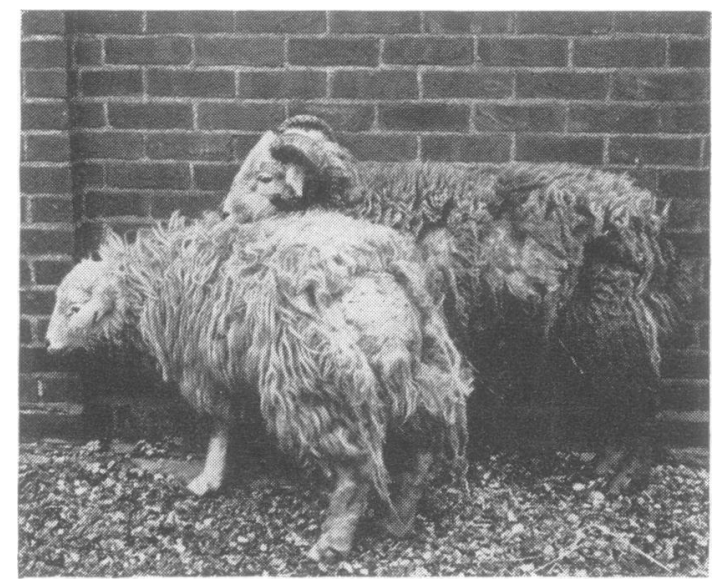

FIG. 1. Scrapie sheep. The rubbing away of the fleece from whic the disease takes its name is apparent. The front animal also has adopted an. unusual stance.

Shepherds and flock-masters become very experienced in spotting early scrapie and it is probable that many animals are disposed of either privately or possibly in the slaughter house.

There is a strikingly genetically dependent susceptibility to the disease. Gordon (1966a) reported that Herdwick showed $78 \%$ susceptibility to intracerebral inoculation of a Moredun stock scrapie brain pool; Swaledale 54\%; Welsh Cheviot $15 \%$; Clun Forest $2 \%$; and Dorset Down $0 \%$. Altogether 24 breeds were studied. Not only was there a variation between breeds noted, but there was also a difference in susceptibility in families within different breeds. In 1961 the late $\mathrm{Dr}$ W. S. Gordon initiated a programme designed to segregate flocks of predictable susceptibility or resistance to experimental scrapie, since the unpredictable susceptibility of sheep to natural scrapie had been known for many years and its familial tendency well $N$ recognized. It was also felt that results with natural experimental sheep scrapie should be regarded a priori as a somewhat different matter from mouse scrapie findings. Recently Nussbaum et al (1975) have summarized the results of a 12-year 으 3

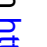


breeding programme from a foundation stock of over 700 Hardwick sheep aimed at producing divergent populations of predictable high and low susceptibility to experimental scrapie. They have found that 'keeping the inoculum and route of inoculation constant throughout, reaction to scrapie would appear to be controlled by two alleles of a single autosomal gene, susceptibility being dominant to resistance'. These findings differ from those of Parry (1962) whose studies of natural scrapie in a large number of flocks involving 10 British breeds led him to the conclusion that the disease was the result of an autosomal recessive gene. Gordon's experiments (1966a) were also consistent with the hypothesis of a recessive inheritance of susceptibility to experimental scrapie.

Nussbaum et al (loc. cit.) emphasize that 'although world wide investigations on the mouse scrapie model have led to remarkable advances in knowledge about the baffling disease, and more particularly its causative agent, the sheep nevertheless remains its principal natural host'. For research on natural scrapie the specially selected flocks should be of great importance. It is in the field of 'slow' infections specially that genetic background is of the greatest significance in determining the result of inoculation of a particular agent.

\section{Spread of scrapie: natural conditions}

Early workers were inclined to believe that the disease was hereditary, but a number of observations not only in the field (Stockman, 1913; M'Fadyean, 1918; Sigurdsson, 1954; Gordon, 1966b) and the experimental transmission of the disease by Cuillé and Chelle (1936) (and subsequently by many others) have made the purely genetic hypothesis very unlikely. Many veterinary surgeons emphasize that possible differences between 'real' (i.e. natural) scrapie and the 'artificial' experimental disease should always be borne in mind. Parry (1962) who emphasizes strongly the genetic component has claimed that contact infection is rare, that the disease is essentially genetic in origin with a transmissible agent arising in the brains of affected sheep as the result of the operation of a lethal recessive gene. Nematode parasites have not been incriminated in lateral spread (Fitzsimmons and Pattison, 1968). Field (1969) has reviewed some of the earlier experimental studies of transmission both in the field and in the laboratory. It is well recognized that peripheral routes of inoculation of scrapie agent are effective (with longer incubation period than intracerebral injection) and Pattison et al (1972) have suggested that a possible route of natural infection in the field might be through ingestion of the placenta expelled by infected sheep. Contamination through the skin by rubbing against infected posts or fences also cannot be ruled out.

Experimental transmission of scrapie to a whole array of animals (excluding guinea pigs) has been successful. Chandler's (1961) transfer to the mouse (with incubation of the order of 5 to 6 months) and later Chandler and Fisher (1963) to the rat (incubation 7 to 9 months) have proved enormously important milestones in facilitating research into the disease, though the new context of the disease must be recognized. Morris et al (1966) claimed that scrapie might spread from affected mice to healthy animals (7 of 200 mice) caged in the same room and suggested the agent could be carried by bedding, dust, etc. Experimental attempts to infect by these means have, however, been negative (Field and Joyce, 1970) and it should be noted that Morris et al failed to make adequate histological study of their positive takes, which were old mice where clinical diagnosis alone is difficult. Field and Joyce (loc. cit.) were also unable to observe the occurrence of scrapie in the offspring of affected mouse parents, over the space of 20 months, though Gajdusek and Gibbs (1968) had reported that 'a small percentage of mice born to females inoculated with scrapie before being bred develop scrapie disease even though they were placed with foster mothers immediately following birth'.

There is now accumulating evidence for the existence of several different strains of scrapie agent (Dickinson and Fraser and their colleagues) characterized by different lengths of incubation and different primary distribution of lesions (vacuoles in mice) in the brain. Two especially clear strains are the 22A and ME7 groups (Dickinson et al, 1968a, b; Dickinson and Meikle, 1969). These workers claim to have identified a gene in mice which controls the incubation of the ME7 scrapie agent, and have named it 'sinc' to denote scrapie incubation period. It comprises two alleles, $\mathrm{s} 7$ and $\mathrm{p} 7$, which show no dominance, the former shortening and the latter prolonging the incubation period. These two known alleles of sinc, s7 and p7, apparently act on some early phase of agent replication in each tissue (Dickinson et al, 1969). Sequential infection of the same mice with strains of long and then short incubation period can result in an extension of the incubation period of the latter (Dickinson, 1971). Hunter (1974) is of the opinion that all forms of the scrapie agent have similar physicochemical properties, but that minor differences may well occur. 


\section{Multiplication of scrapie agent}

The multiplication rate of the scrapie agent is subject to genetic control (see above) and indeed very recently Dickinson et al (1975) have suggested that the incubation time of scrapie may exceed the natural life span. This is deduced because the agent always appears in the spleen before brain, and death from 'natural' causes may supervene before a detectable concentration of agent occurs in the brain with accompanying clinical disease. They go on to point out that there 'seems to be no reason why this will not occur within other members of this group of diseases. It is, therefore, possible that a greater number of individuals are infected with one of the agents causing transmissible encephalopathies or dementias, such as Creutzfeldt-Jakob disease in man, than the number of cases which occur.' The relevance of these thoughts to the problem of ageing will become apparent below when the relation of scrapie and the ageing process is considered in some detail.

Eklund et al (1967) showed that scrapie agent spread rapidly to all organs of the body soon after intracerebral or peripheral inoculation in the mouse, though neither Eklund et al (1965) nor Pattison et al (1964) could demonstrate the agent in the blood. Clarke and Haig (1967) were successful in a few cases, but Field et al (1968), looking at very short intervals after inoculation, showed regular access to the blood with presumable metastasis in the organs, especially those of the lymphatic system. Indeed the agent appears later in the brain than in lymph nodes and spleen, seeming to proliferate preferentially there. Not only does the agent spread by the blood but settles in the segments of the neuraxis related to the inoculation site producing there the earliest morphological changes of scrapie-astroglial hypertrophy (Field, 1967a). In this respect the agent is similar to a neurotropic virus such as poliomyelitis. There is some evidence also that scrapie undergoes an 'eclipse' phase in the brain (Field et al, 1971).

\section{Scrapie in the mouse}

\section{A. Clinical features}

The earliest signs are some degree of slowing in movement which may alternate with periods of excitement, or there may be periods of a few seconds during which the animal suddenly stands still in an almost cataleptic state. Such changes occur about 10 to 12 weeks after intracerebral inoculation of $0.02-0.03 \mathrm{ml}$ of a $10^{-1}$ sterile scrapie brain emulsion. Later the whole animal becomes more rigid and becomes a monobloc. Males commonly show priapism with incrustation round the penis and distended bladder. The tail stiffens and can sometimes be moulded into the shape of a question mark ('the scrapie question'). The animal is readily pushed over as a solid block. However, if put into an ether pot for anaesthesia, it may react violently. Indeed careful examination by controlled visual or auditory stimuli reveals hyperreactivity quite early in the disease at a time when astrogliosis in the brain is just beginning (Savage and Field, 1965). Considerable emaciation occurs towards the end, though some animals become very fat.

\section{B. Pathological changes}

Specific pathological changes are essentially limited to the brain and spinal cord, where the earliest sign is hypertrophy of astroglial cells. Neuronal vacuolation is more common in sheep (Fig. 2), but is found with certain strains of agent in mice, too (Pattison, 1957; Chandler, 1961). Neuronal vacuolation appears to arise by dilatation of endoplasmic reticulum sacs (Field and Raine, 1964). Status spongiosus, especially of the grey matter, is very characteristic of scrapie in the mouse (Fig. 3) and reminiscent of the spongy encephalitides of man (Jakob-Creutzfeldt disease: Kuru).

The precocious astroglial hypertrophy in the young mouse (Fig. 4) or rat (Fig. 5) with scrapie is quite like that found in the normal very old animas (Field, 1967b), and indeed 'blind' slides sent to M Pattison and Dr Zlotnik, both with vast experience in the diagnosis of scrapie, elicited requests for information of the age of the animal before a diagnosis could be sure. More recently, Fraser and Bruce (1973) have described argyrophilic plaques of senile type in mice inoculated with certain scrapie strains. These resemble the plaques found in Kuru (Beck and Daniel, 1965; Field et al, 1969). The pathological resemblances between scrapie, kuru, multiple sclerosis, and old age have been evaluated by Field (1967b). (It may be said at once, in anticipation of what is to follow, that multiple sclerosis is unrelated to the other three conditions.) Astroglial hypertrophy, amyloid bodies, intra-axial orientated tubules, spiral filaments, filagree arrangements, have all been found in the scrapie-kuruJakob-Creutzfeldt complex (reviewed by Field, 1969.) The suggestion that kuru and scrapie, despite admittedly widespread 'non-specific' changes are essentially 'system diseases' affecting the cerebellar system (and in scrapie, too, the neuro-hypophysical complex) (Beck et al, 1964; Beck and Daniel, 1965) has received little support as more and more studies have emphasized the widespread character of the changes (Kakulas et al, 1967). 


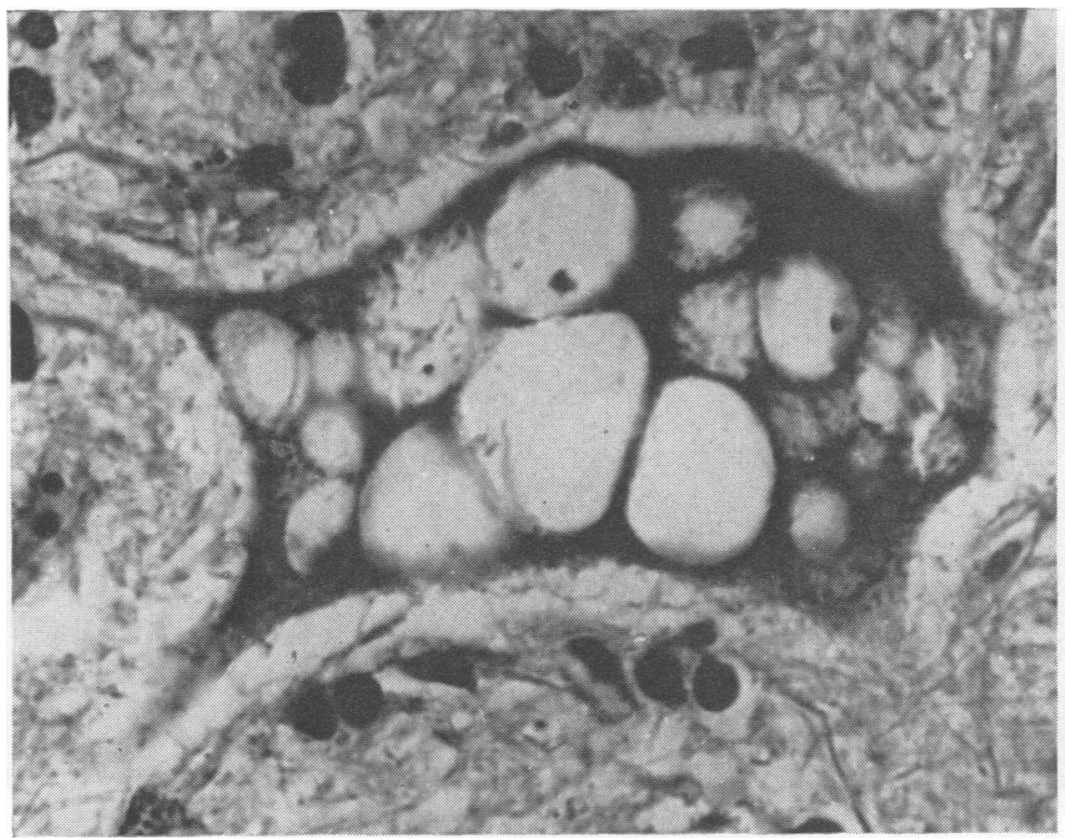

FIG. 2. Anterior horn cell of sheep with natural scrapie showing multilocular vacuolation ('bubble cell'). The Nissl substance is commonly well preserved in such cells and electron-microscopy shows the vacuoles to be derived from expanded endoplasmic reticulum sacs. (H \& $E \times 800$.)

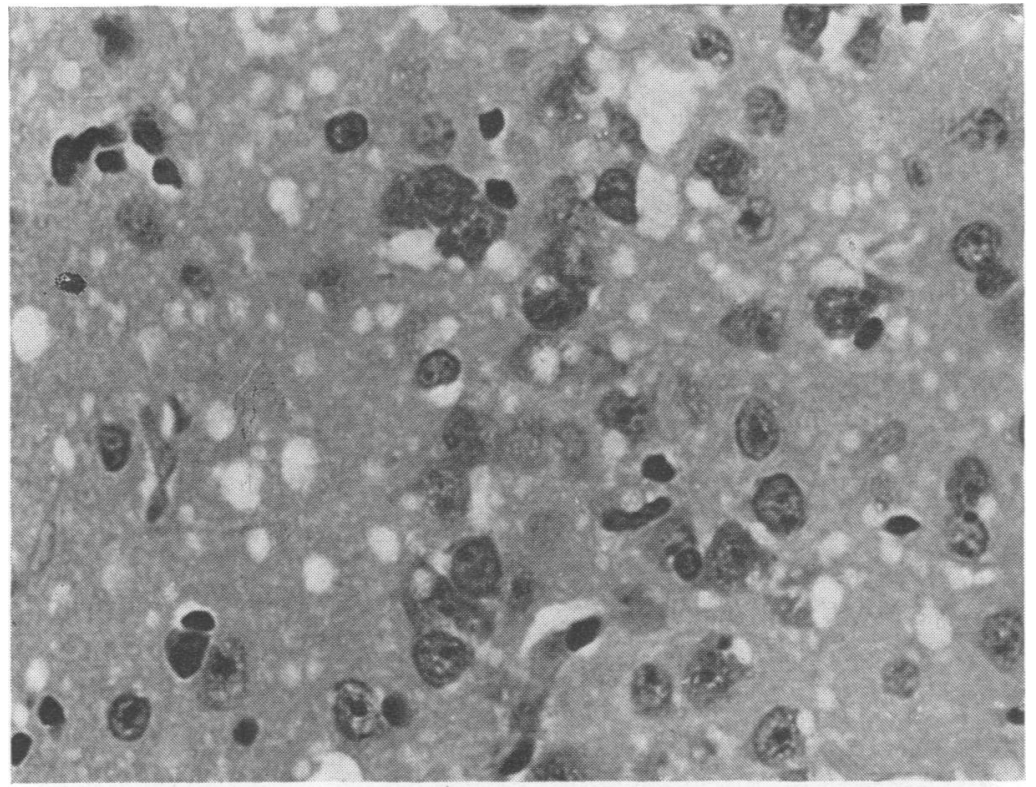

Fig. 3. Cerebral cortex of mouse with scrapie: note vacuolation of the 'background substance' which later becomes very marked. These vacuoles are in part made up of grossly dilated astroglial processes. ( $\mathrm{H} \& \mathrm{E} \times 800$. $)$ 


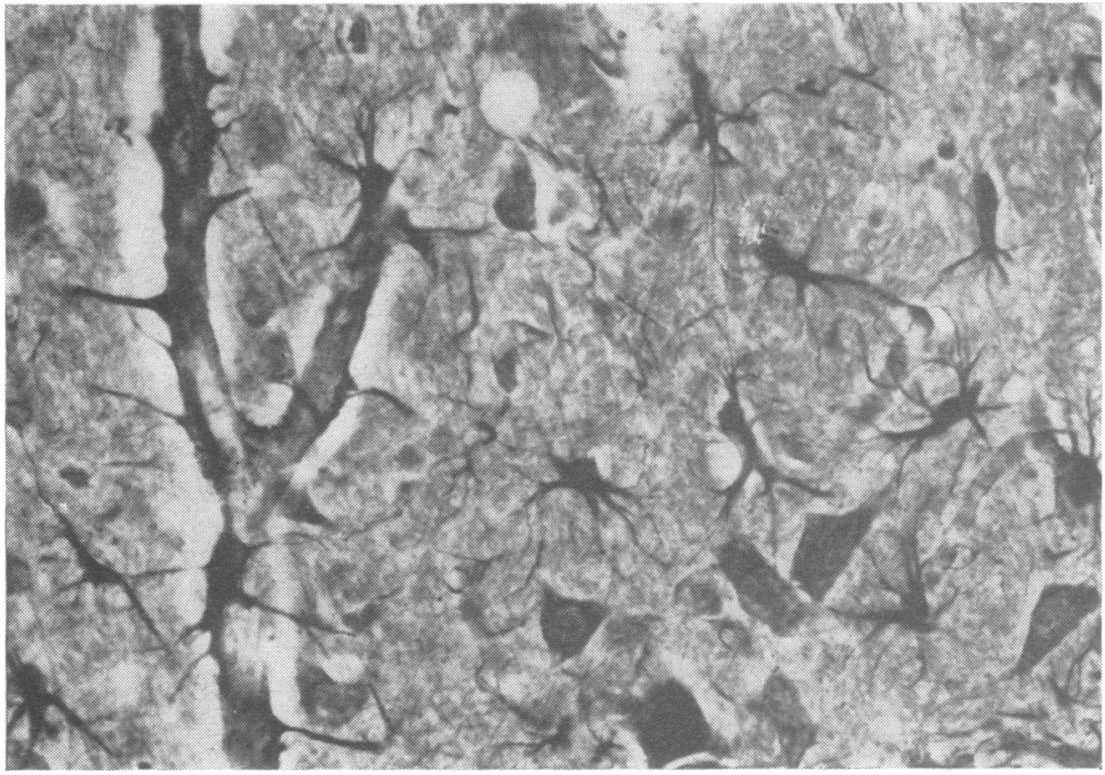

FIG. 4. Normal old mouse ( 2 years 3 months). Here the astrocytes are enlarged and stain well. The astrocytes of early scrapie stain like this, too. In the young normal mouse (up to about 9 months) astrocytes stain very faintly with thin wispy and relatively few processes. (Gold chloride $\times 500$.)

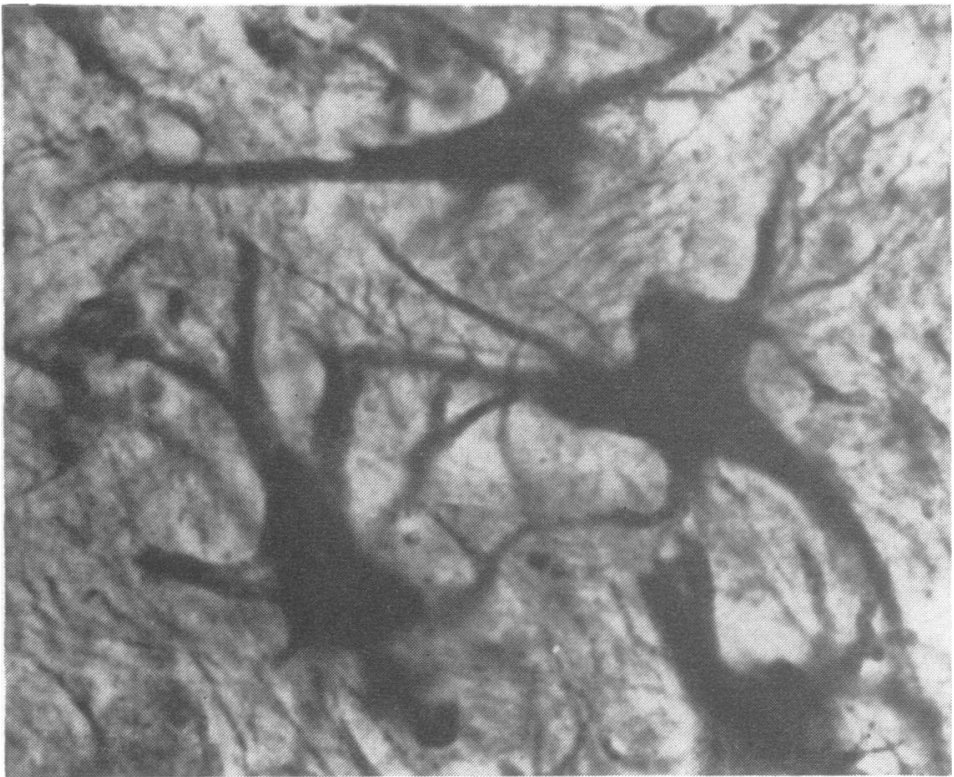

FIG. 5. Astrocytes of advanced scrapie in the rat showing well-marked hypertrophy. (Gold chloride $\times 1024$.) 
The notion that scrapie is essentially a disease of the central nervous system has not gone unchallenged. McGowan (1914) pictured the disease as one primarily of muscle resulting from infestation with sarcocystis tenella, and, as recently as 1956 , Bosanquet, Daniel, and Parry concluded that the principal pathological lesion in scrapie was a degeneration of skeletal muscle and sometimes of the myocardium - the picture being essentially one of a polymyositis or a more acute muscular dystrophy. They concluded that 'there is no sound evidence that scrapie is due to an infection of the central nervous system'. Detailed study of the muscles (Hulland, 1958) has, however, failed to substantiate lesions, and it appears that a muscular dystrophy was present as an incidental disease in the original material, though Beck et al (1964) found a few lesions of the original type they described.

An interesting feature of scrapie (as well as JakobCreutzfeldt disease and multiple sclerosis) is the propensity for vigorous growth which explants of, even adult, infected tissue show (Gustafson and Kanitz, 1965; Field and Windsor, 1965; Haig and Pattison, 1967; Clarke and Haig, 1970), though it has not yet been possible to infect any already established cell line with the agent.

\section{Properties of scrapie agent}

These are remarkable for the stability of the agent in face of a large number of agencies which kill ordinary viruses. Only periodate (Gibbons and Hunter, 1967) and alcoholic iodine solution (Bell et al, 1972) seem at all effective. Field (1969) and Hunter (1974) have reviewed the properties in detail. Of special note is resistance to autoclaving (20 psi for 30 minutes: $10^{-1}$ suspension)-though there was pronounced diminution in titre. Even re-autoclaving still produced disease in 3 of 6 mice after the prolonged incubation period of 13 to 15 months (and it may be noted that this is the incubation period with some of the most 'interesting' and 'unorthodox' scrapie results). Whether there is an irreducible minimum of infectivity which cannot be eliminated by repeated autoclaving remains to be tested (Field, 1969). The agent shows a quite remarkable resistance to formalin (Pattison, 1965), even storage in 10 per cent at room temperature for 28 months did not destroy activity.

Of outstanding significance, however, is the now well-authenticated observation by Alper et al (1966, 1967) of the truly remarkable resistance of scrapie agent to ionizing radiation and ultraviolet light. In two separate experiments Field et al (1969) fully substantiated the original claims, deriving figures almost identical with those of Alper et al, even 25 megarad. of irradiation completely failing to cause inactivation at a dilution of inoculum of $10^{-2}$ and 2 out of 6 mice dying at $10^{-4}$.

There is no doubt the agent is very small by ordinary viral standards. Kimberlin et al (1971) arrived at a figure of $5 \times 10^{7}$ daltons. Filtration experiments over the years have also progressively reduced the size of the effective agent, and indeed, since it has never been possible to separate the agent from cellular membrane fragments, many measurements must merely reflect the degree of break up of the tissue tested. The significance of this intimate (if not indeed integral) association with cell membrane will emerge below. The most direct evidence for the extremely small size of the active scrapie agent comes, however, from the abovementioned experiments of Dr Tikvah Alper and her collaborators, who calculated the extremely small size of the effective target.

Among the remarkable properties of the scrapie agent, the only ones that are clearly in line with those of recognized viruses are the invasion of the central nervous system along segmental lines and the 'eclipse phase' referred to above. Nevertheless, many of its extreme properties can be matched or nearly matched by individual properties of other accepted viruses. The very small size of the infective agent was at first thought to rule out its viral nature-and the writer still prefers to refer to 'agent' rather than 'virus'. The calculated target size of the active scrapie-producing agent was at first thought too small to comprise an adequate selfreplicating coding mechanism. Diener (1971, 1974), however, has recently introduced the concept of viroids as much smaller agents of infectious disease. For the most part they appear to be short strands of RNA with a molecular weight about 75 to 100000 daltons capable, when introduced into a susceptible host, of apparent replication leading in some cases to disease. The first viroid to come to light was the agent of potato spindle tuber disease, long assumed to be 'viral'. In 1967 Diener and Raymer claimed the infectious agent to be a free RNA and that recognizable viral particles are not found. Additional plant diseases (chrysanthemum stunt and citrus exocortis) have since then also been claimed as caused by viroids (reviewed by Diener, 1974). Again the low molecular weight of viroids (plant) raises the question as to how such RNAs can contain sufficient genetic information to induce replication in susceptible hosts. Thus, for potato spindle tuber disease the molecular weight would enable coding for some 70 to 80 amino acids, i.e. barely sufficient to code for a very small protein. It 
is all the more surprising that viroids do seem able, in certain hosts, to incite severe disease. These problems are considered by Diener (1974) with various ingenious hypothetical constructs: Diener himself (1972) has proposed that scrapie agent may be a viroid coming within Alper et al's (1966) calculated target size for the active scrapie agent of $1.5 \times$ $10^{5}$ daltons, the size which they considered 'implausibly small as a nucleic acid code'. Many, at least, of the extreme properties of the agent might be accounted for by its viroid nature. The enigmatic nature of the scrapie agent has generated numerous hypotheses, including the belief that it is a classical small virus with somewhat unusual properties (some of which can be individually matched amongst recognized viruses) (Stamp, 1967); that it is a small DNA virus with a polysaccharide coat (Adams and Caspary, 1967); that it is a pro-virus (Parry, 1962); that it is a histone-associated material (Pattison and Jones, 1967); that it is a self-replicating polysaccharide (Field, 1967b); that it is present in normal brain and is unmasked by various procedures (Pattison and Jones, 1968b); that it is an agent that brings about physicochemical alterations in cell membranes (Gibbons and Hunter, 1967); and that it may be a provirus capable of binding only to cell membranes when a linkage substance is supplied (Adams and Field, 1968). Recently Carp et al $(1972,1973)$ and Licursi et al (1972) have claimed that the percentage of polymorphonuclear neutrophils in C57B1 mice was reduced permanently after injection of either scrapie or multiple sclerosis tissue. The decrease was detected within three days of the injection of scrapie and persisted throughout the three months of the preclinical stage of the disease. In their work they did not use material from nervous diseases other than multiple sclerosis, so that the specificity of the phenomenon for multiple sclerosis cannot be assessed. Technical difficulties in the assay for scrapie proposed by Carp's work have been assessed by Dickinson et al (1974) who sound a note of caution in their general confirmation of the scrapie report by Carp et al. On the other hand, Brown and Gajdusek (1974) repeated Carp's experiments (including using some of his original material) with negative results, so that the reality, specificity, and nature of the PMN depressing factor remains in question. Since Carp's work linked scrapie and multiple sclerosis, it may be appropriate at this point to make clear the current situation in respect of the association between scrapie and multiple sclerosis. In 1947 Campbell et al reported the development of multiple sclerosis in 4 of 7 research workers at Cambridge studying swayback in sheep. It is now recognized that swayback is a form of dysmyelogenesis in lambs associated with copper (and perhaps also other trace elements such as molybdenum) deficiency in the pasture on which ewes are raised. Nevertheless, Campbell's cases were striking and their attribution to chance appeared remote. Attempts by Sutherland and Wilson (1951) to transmit multiple sclerosis to sheep were unsuccessful over a period of 17 months. When, however, Sigurdsson (1954) introduced the new concept into our thinking about the time scale of development of an infection ('slow' infections) it reopened once again the issue of an infective aetiology in multiple sclerosis, and indeed epidemiological data in the disease could be arranged so as to lend the idea support (Schapira et al, 1963).

Attempts to transfer multiple sclerosis to a whole host of animals (including sheep) and tissue cultures were unsuccessful in Newcastle, but in Reykjavik, Palsson et al (1965) reported the highly unexpected emergence of rida (the Icelandic scrapie) in sheep after 18.5 months average incubation reduced to 10.8 on passage (a characteristic of scrapie when the species barrier is crossed). Further attempts at Newcastle, at Compton A.R.C. (Mr I. H. Pattison), and by Dick et al (1965) were unsuccessful. In 1966 Field reported the appearance of scrapie in mice after blind passage of multiple sclerosis biopsy material combined with $\mathrm{X}$-irradiation. Unforo tunately, scrapie had by this time been introduce into the Newcastle buildings (following the Icelan dic findings) and, as the author himself wrote at the time, 'it is important that attempts to pass multiple sclerosis into mice should be made in laboratories not working with scrapie materials at all'. Later attempts to repeat the transmission were unsuccessful. The same criticisms might be levelled at the claim to have transmitted kuru to mice (Field, 1967c), though recently Brownell et al (1975) have claimed successful transmission of JakobCreutzfeldt disease to mice after an 18-month incubation period. Because of the essentially similar nature of scrapie, kuru, and Jakob-Creutzfeldt disease, it is indeed probable that the latter two will be eventually established in mice.

The development of the linoleic acid depression 은 (MEM-LAD) test for multiple sclerosis (Field et al, 1974a ; Jenssen et al, 1974, 1975) enabled the testing of scrapie sheep for susceptibility of their lymphocytes to suppression by linoleic acid. They were o found not to show the high sensitivity associated N with multiple sclerosis (Field $e t a l, 1974 b$ ) and a re- N lation between the two conditions appears that much 0 less likely (Field, 1975). Though the original observations were very probably wrong, they did provoke a good deal of interest in possible 'slow' 
infection aetiology of multiple sclerosis, even though the mantle (for no very good reason (Field, 1975)) has recently fallen on measles.

\section{Membrane hypothesis of scrapie}

This elegant hypothesis of the scrapie mechanism put forward by Gibbons and Hunter (1967) postulates that 'the presence of the agent of scrapie in a cell may represent an alteration in the basic threedimensional configuration of a commonly occurring unit membrane structure. Such an alteration would not necessarily require the introduction of any new molecular components into the cell affected by scrapie'. This highly novel idea deserves careful consideration in view of the ageing changes to be described below. Certainly all attempts to isolate a specific scrapie agent from cell membrane structures have been unsuccessful. Gibbons and Hunter postulate that the determining factor in scrapie pathogenesis is a steric rearrangement of the membrane-and specificially suggest it is likely to be a rearrangement in the sugar or oligosaccharide residues attached to it. In an elaboration of their theory, Hunter et al (1968) have set out the three statements basic to their hypothesis.

(1) The scrapie agent is an integral part of a unit membrane structure of affected cells.

(2) The alteration in membrane structure probably involves primarily the polysaccharide chains of the membrane glycoprotein molecules.

(3) Known mechanisms for the replication of polysaccharide might be applicable to the biosynthesis of a membrane as a whole.

Their hypothesis owes much to the model of membrane regulation by colicins proposed by Changeux and Thiéry (1967) who suggested that a colicin molecule binding to the plasma membrane of a susceptible cell would alter the conformation of the membrane subunits to which it was attached into some 'damaged' form. Changeux et al (1967) furthermore proposed a 'lattice constraint' operating between the repeating protomers which constitute the membrane, so that if one subunit is constrained to a fixed structure for any reason, adjacent subunits will fall into the same conformation by a process analogous to the flipping-over of a pack of cards standing on edge. It is possible to imagine that the incorporation of a fragment of scrapie membrane into the cell membrane of a new host cell may lead to an outward spreading ripple of transformation which, when it became sufficiently extensive, would manifest itself as disease. It is interesting that an abnormal sodium/potassium ratio has been reported in the brain of the mouse developing scrapie (Field and Windsor, 1965), a finding that might well be related to progressive alteration in membrane make-up.

\section{Immunological observations}

The suggestions by Hunter and his group lead naturally to consideration of immunological phenomena in scrapie, since the membrane changes they postulate might be expected to lead to immunological consequences. A long established curiosity of scrapie has been failure to detect any specific immunological response (Chandler, 1959; Pattison et al, 1964; Clarke and Haig, 1966; Clarke, 1968; Gajdusek and Gibbs, 1968), though, of course, the limitations of methods must always be borne in mind. Gardiner (1965) did, however, record some collateral observations which, in retrospect, did not receive the attention they deserved. He found that, when tissues from normal and scrapie animals were used as antigens in rabbits, 'spleen preparations from scrapie-affected animals were much better from an antigenic point of view than were similar preparations from non-scrapie tissues'. He further went on to suggest that 'some tissue components that are poorly antigenic in the non-scrapie spleen become improved antigenetically in the scrapie spleen', though his experiments could not determine the nature of these materials. Two excellent recent reviews of scrapie (Fuccillo et al, 1974; Hunter, 1974) omit these important findings of Gardiner, though the former reports Gardiner and Marucci's (1969) later work to the effect that the immune response is not interfered with in the scrapie mouse.

The development of a new and exquisitely discriminatory method of measuring lymphocyte sensitization in both man and animals-the macrophage electrophoretic mobility (MEM) test (Field and Caspary, 1970; Caspary and Field, 1971-with an experimental protocol in extenso; Shenton et al, 1973; Shenton and Field, 1975) has made accessible to study minor changes in antigenicity (as evidenced by cellular sensitization). Changes in membrane constitution in scrapie and also in kuru and Jakob-Creutzfeldt disease, postulated by Gibbons and Hunter, have been studied with this method. For such minor changes the MEM test is especially useful (Carnegie et al, 1973; Westall, Carnegie, and Field-unpublished), since variations in a single aminoacid residue in an antigen are readily detectable.

Following the inspired recognition by Hadlow (1959) of the resemblance between scrapie and kuru (Fig. 6) and his seminal suggestion that at- 


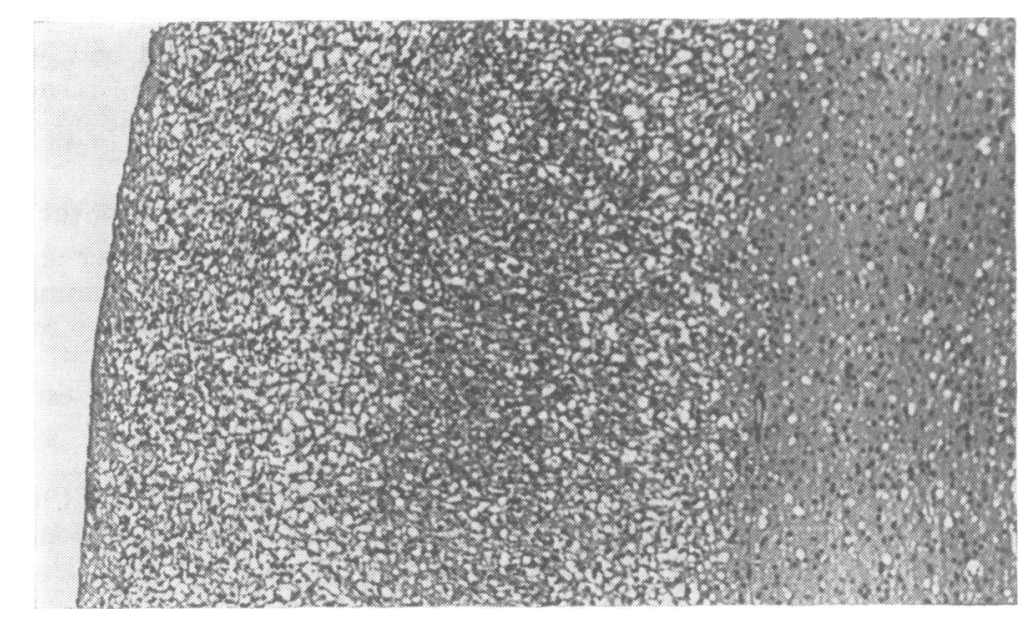

FIG. 6. Kuru in chimpanzee. Occipital cortex showing marked vacuolation, here showing a laminar appearance. (H \& $\mathrm{E} \times 56$.)

tempts should be made to passage the disease into laboratory primates, the Washington group led by Gajdusek have had striking success in establishing kuru in chimpanzees (confirmed in Newcastle in 1971) and have extended their work later to JakobCreutzfeldt disease (also repeated in Newcastle) (Gajdusek et al, 1966, 1967; Gibbs et al, 1968; Field and Shenton, 1973a). Kuru has also been transmitted to the spider monkey (Ateles geoffreyi) (Gajdusek et al, 1968). Recently, too, it has been claimed that scrapie has been transmitted to the cynomologous monkey (Gibbs and Gajdusek, 1972). Transmissible mink encephalopathy (TME), first described by Hartsough and Burger (1965) and Burger and Hartsough (1965) after an outbreak in Wisconsin mink farms, has general features very reminiscent of scrapie (Field, 1969; Marsh and Hanson, 1969; Marsh et al, 1969). Transmissible milk encephalopathy has, moreover, now been transmitted to Old and New World monkeys (Marsh et al, 1969; Eckroade et al, 1970; Gibbs and Gajdusek, 1973). When Gibbs et al, in 1968, reported the transmission of Jakob-Creutzfeldt disease to chimpanzees, they recorded that, though the changes in the brain showed certain features in common with kuru, 'there were other features not characteristic of kuru that enabled this brain to be easily distinguished from that of the animal with experimental kuru'. However, subsequent studies (as has been the case with the Newcastle kuru and Jakob-Creutzfeldt material) have tended to diminish the emphasis on these differences. Indeed Field (1969) thought it 'highly probable that (JakobCreutzfeldt disease)... will turn out to be kuru- scrapie and it is likely that Jakob-Creutzfeldt disease is the Western analogue of kuru'. Gibbs and Gajdusek (1971) appear to have accepted the essential unity of these diseases, and speculate that 'the initial source of kuru agent might have been a rare sporadic occurrence of a case of Jacob-Creutzfeldt disease in a Fore New Guinea Highlander, and that widespread contamination of the people in the mourning ritual of cannibalistic consumption of dead relatives, with inoculation of themselves and $\mathrm{O}$ their infants, may have only served to disperse the infection widely in a pseudo-genetic pattern determined by the familial pattern of mourning for kinsmen who were kuru victims'. In retrospect, it is instructive and salutary to recall the efforts initially made to explain kuru on a purely genetic basis (Bennett et al, 1958, 1959).

As with scrapie, so with kuru and JakobCreutzfeldt disease, no circulating antibodies have been found, even though most diligently sought. Benfante et al (1974), for example, screened 201 kuru patients and 49 chimpanzees with kuru for antibodies against 65 infectious agents, with negative results.

Against this uniformly negative background, cellular investigation studies with the MEM method referred to above have yielded some highly unexpected results. In principle, the MEM method for measuring lymphocyte sensitization to an antigen depends upon the interaction of lymphocytes with antigen to produce a lymphokine with the property of causing normal guinea-pig macrophages to travel more slowly in an electric field. This lymphokine has been provisionally called macrophage 
slowing factor (MSF) and may well be identical with the well known macrophage inhibitory factor (MIF) which is liberated in the widely used macrophage migration inhibition (MMI) test of David et al (1964) (Bloom and Bennett, 1966). While in the MMI test the inhibition of active migration of normal macrophages from the mouth of a capillary tube is used as an index of lymphocyte-antigen interaction, in the macrophage electrophoretic mobility (MEM) test, the slowing of passive migration in an electric field (i.e. change in surface charge) of normal macrophages is used. The method was indeed thought up on the assumption that a lymphokine which interferes with active migration of macrophages would very likely also induce an alteration in their surface charge.

The MEM test has been described with very full details and the results of extended experience in the works referred to above. All measurements of migration speed of normal guinea-pig macrophages have been made in a Zeiss microelectrophoresis apparatus (cytopherometer) and have been carried out 'blind' on numbered and coded specimens, and those studied in one session have usually been derived from several different experimental sources. For example, among one batch of 25 numbered bijoux bottles presented to the observer, might be lymphocyte tests from a patient with multiple sclerosis, a scrapie sheep, a patient with sarcoidosis, a possible cancer patient, and a normal subject or a pregnant woman. Ten suitable macrophages (Shenton $e t a l, 1973$ ) are measured in each direction of the potential difference so that a mean and standard deviation may be calculated. If $t_{e}=$ time when antigen present (i.e. antigen + lymphocytes + macrophages); $t_{c}=$ control time (no antigen present), then $t_{e}>t_{c}$ and $\frac{t_{e}-t_{c}}{t_{c}} \times 100$ is a measure of the lymphocyte sensitization. In fact, it would be more accurate to use $\frac{t_{e}-t_{c}}{t_{e}} \times 100$ as the statistic for slowing of speed, but for the actual magnitude of figures recorded the difference is only slight. The statistical significance between the experimental and control (or two experimental) means may be evaluated by Student's $t$ test. With practice, as the operator becomes more skilled in the use of the machine, his readings show less and less scatter, so that standard deviations become lower to the point where percentage differences as low as 6 or $7 \%$ correspond to $\mathbf{P}<0.01$. The original MEM test as applied to cancer has been confirmed by Pritchard et al (1973), Preece and Light (1974), Goldstone et al (1973), though Dr Irvine's group were unable to confirm their original results (Lewkonia et al, 1974; MeyerRienecker et al, 1974; and M. Müller, personal communication). No one yet appears to have applied the method to the scrapie-Kuru-JakobCreutzfeldt problem.

\section{Sensitization in scrapie}

Because of Gardiner's observations (1965) referred to above, the cellular response to scrapie as opposed to normal tissue was determined. For this, normal guinea-pigs were immunized by inoculation of $10^{-1}$ suspensions of normal brain or spleen and similar scrapie animal tissues. Eight to ten days later the animals' lymphocytes were studies for sensitization to a suspension of scrapie and normal brain or spleen (and later other organs, too). In the case of guinea-pigs which had been immunized with normal brain (say), the lymphocyte response to scrapie brain was greater than to normal brain, so that the scrapie-normal difference was positive. If scrapie brain had been used for immunizing the guinea-pigs, the response to scrapie brain was considerably greater while it remained much the same to normal brain, so that the scrapie-normal difference was increased. This increased difference was also found with scrapie spleen and other scrapie tissues. When the initial scrapie material inocula were of known biological titre, it quickly became apparent that the scrapie-normal difference developed in the guinea-pig ran parallel to the titre, so that it became possible to evolve a rapid method of demonstrating scrapie and indeed of titrating it in 8 to 10 days instead of the 6 to 8 months needed for biological titration (Field and Shenton, 1972, 1973b). In the sheep it was found that, as scrapie developed, the blood lymphocytes began to show raised scrapienormal difference which could be used for diagnosis (Field and Shenton, 1974). It thus appeared that sensitization to scrapie agent (or something associated with the scrapie agent) was occurring as the disease developed under natural conditions.

At this point there were available in Newcastle chimpanzees which had been injected with kuru and Jakob-Creutzfeldt disease brain. When their lymphocytes were tested, they, too, showed a pronounced increase in scrapie-normal difference. Control studies were, however, carried out with a variety of other neurological diseases, including multiple sclerosis, glioma, and neurosyphilis. These, too, showed raised scrapie-normal differences. The only common pathological feature among this disparate group appeared to be astrogliosis, which was a prominent feature of all the conditions which gave high scrapie-normal 
difference. It is of special interest that a very early (9 months' history) case of multiple sclerosis showed a well-raised scrapie-normal difference (reminiscent of the many descriptions of the earliest pathological changes of multiple sclerosis going back to Charcot, 1872, which stress precocious, if not indeed initiatory, astroglial reaction). These results suggested that what was being measured was not something specific to scrapie agent but something associated with hypertrophied astroglia-perhaps some antigenic determinant associated with activated glia (Field and Shenton, 1973a). On the other hand, exactly the same high scrapie-normal difference resulted when scrapie spleen, kidney, or liver was injected into guineapigs-where there was no question of astrogliosis. It may be that the antigenic changes induced by the presence of scrapie agent result in morphological change only in the case of astroglia but not with other cell types. If astroglial cells are made to undergo hypertrophy to produce a 'pseudo-scrapie' state by feeding mice with cuprizone (Pattison and Jebbett, 1971) then this brain, too, on injection into guinea-pigs produced an increased scrapie-normal difference.

A full record of the large number of tests carried out with normal, miscellaneous disease, glioma, other neurological disease, neurosyphilis and multiple sclerosis, as well as with kuru and JakobCreutzfeldt disease is given by Field and Shenton (1973a) and a small illustrative selection in the Table.

When further chimpanzees were injected in Newcastle with Jakob-Creutzfeldt, kuru, multiple sclerosis, and normal brain material, the opportunity was taken of making longitudinal estimations of scrapie-normal difference on their lymphocytes (Field and Shenton, 1975). It was found that $\vec{\omega}$ Jakob-Creutzfeldt, kuru, and multiple sclerosis $\dot{\sigma}$ brain (but not normal brain) produced a pronounced initial but transitory scrapie-normal

TABLE

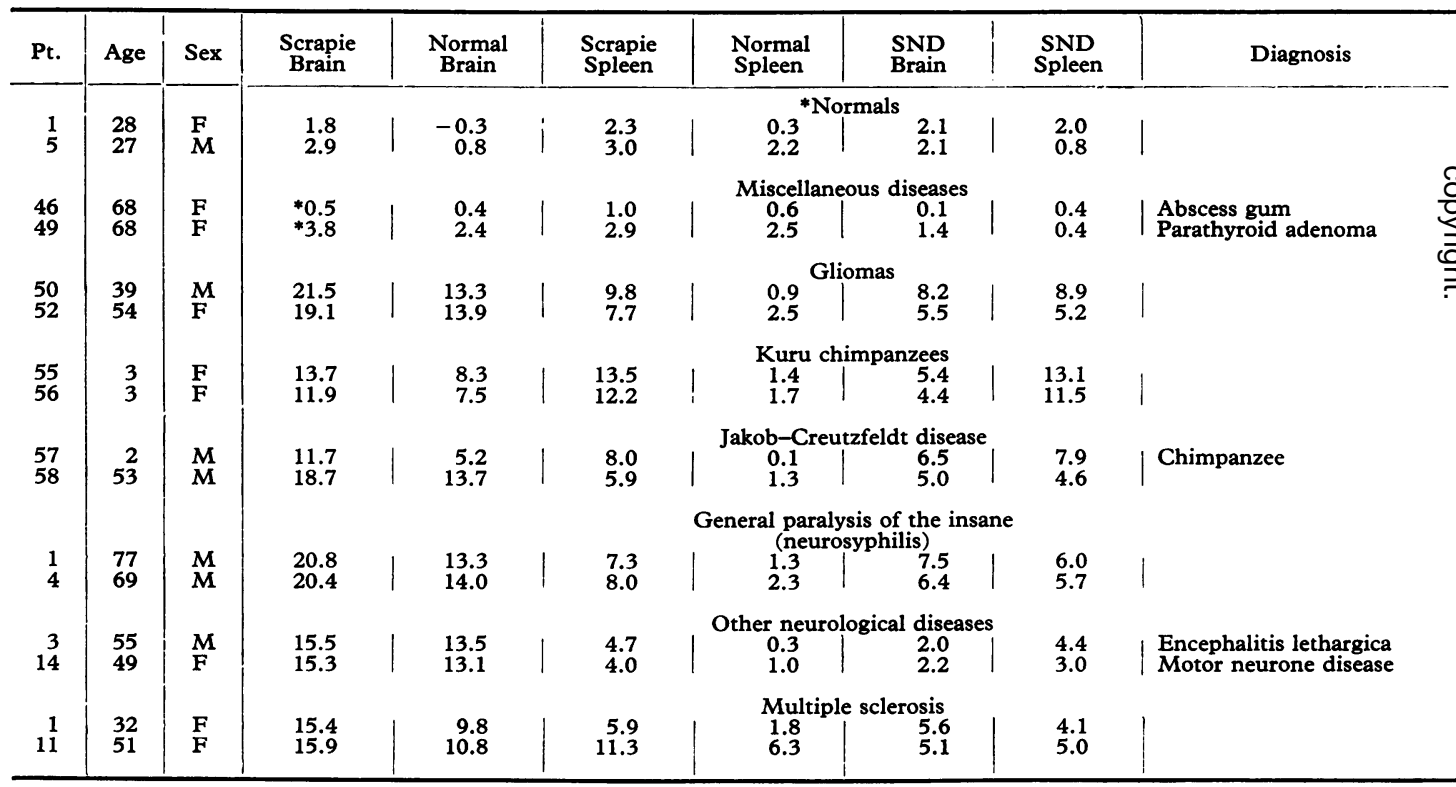

Significances (on total results available)

\begin{tabular}{l|c|c}
\hline & Brain & Spleen \\
OND v MS & $<0.001$ & $<0.001$ \\
OND v GPI & $<0.001$ & $<0.001$ \\
OND v Normal & $0.02-0.01 * *$ & $0.005-0.001$ \\
MS v GPI & $0.05-0.025 t$ & $0.5-0.4$ \\
\hline
\end{tabular}

OND, other neurological disease; MS, multiple sclerosis; GPI, general paralysis of the insane.

* No increase in sensitization to brain: in the other conditions listed there is increased lymphocyte sensitization to brain (because of destructive lesions) and so high values with scrapie brain, too.

** Accepted as significant.

+ Not accepted as significant. 
difference, as expected. This remained low for the ensuing few months and then in the case of JakobCreutzfeldt and kuru rose again, while with the multiple sclerosis it did not. This was taken to mean that the infections (Jakob-Creutzfeldt and kuru) had 'taken' even though the animals were clinically well (and that no 'take' had occurred with multiple sclerosis). In other words, there had been 'internal sensitization' against newly developed antigens in the Jakob-Creutzfeldt and kuru inoculated animals, which gave the same reactions as did scrapie sheep lymphocytes when tested for scrapie-normal difference.

Because of the general resemblances between scrapie-Jakob-Creutzfeldt disease-kuru on the one hand, and the ageing process on the other, referred to above, attempts were made to see if the same new 'scrapie-like antigen(s)' also appeared in normal ageing. Experiment soon showed that lymphocytes from normal old people gave no increased scrapie-normal difference, i.e. there was no spontaneous sensitization to any new antigens which might have appeared in ageing tissue; or, to put it another way, if new antigens were emerging, then they were being recognized by the body as 'self'. But what would happen if a guinea-pig were presented with young normal tissue and old normal tissue and asked if its recognitional system accepted them as equivalent antigens? Here the answer was clear (Field and Shenton, 1973c). As the animal (mouse or man) from which various tissues were taken became older, the scrapie-normal difference response induced in the guinea-pigs became greater, so that a clear 'ageing curve' could be plotted (Fig. 1). Moreover, the tissues 'aged' (in terms of the scrapie-normal difference they developed) at somewhat different rates. Both in man and mouse then, as the tissues aged, new antigen(s) appeared which were similar to (if not identical with) that appearing in scrapie tissues of young animals. An unexpected link residing in the antigenic make-up of the tissues was thus established between the ageing process and the development of scrapie.

The question now arose as to the degree of similarity between the new antigenic component(s) in scrapie tissue and those in Jakob-Creutzfeldt disease, kuru, and ageing. This problem could well be attacked by the method employed by McDermott et al (1974) in examining the relation between encephalitogenic factor and measles virus antigen. Briefly it depends upon a marriage of affinity chromatography and 'titration' of the number of specifically sensitized lymphocytes by the MEM method. Thus, it has been shown that, if measles antigen be put on to a column of Sepharose-Biogel beads and lymphocytes sensitized to encephalitogenic factor put down the column, then a certain proportion of the lymphocytes bind to the measles antigen, and the number coming through the column can be estimated and compared with that put in by the MEM method (Caspary and Field, 1974). By putting 'ageing antigen' on column and passing scrapie sensitized cells down the degree of cross-sensitization might be estimated. Indeed, the technique should be applicable mutatis mutandis to the very wide problem of antigenic determinant sharing in immunology.

Clearly the development of 'new scrapie-like antigens' in ageing tissues is directly related to the ingenious suggestion of Gibbons and Hunter (1967) regarding molecular rearrangements in cell membranes as the underlying 'cause' of scrapie. If this is so, then scrapie (and kuru as well as JakobCreutzfeldt disease) is a premature development under an artificial stimulus (the injection of an already scrapie-aged fragment) of the spreading ageing rearrangement of the cell membranes.

It is interesting that the ageing change appears in all tissues examined, but at somewhat different rates (Fig. 7). A sample of blood cells (either red

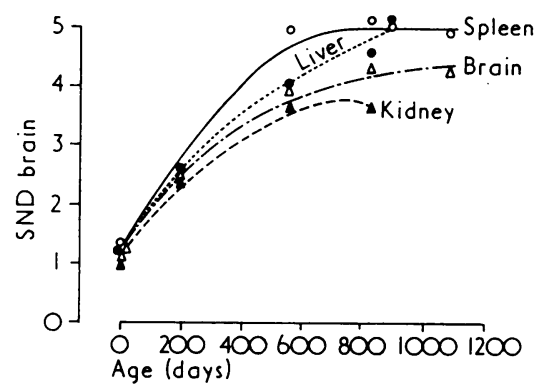

FIG. 7. Guinea-pig lymphocyte sensitization to scrapie and normal brain test antigens (SND = scrapie-normal difference) after injection with mouse tissues of different ages. (Courtesy of Gerontologia, 19, 211-219, 1973.)

or white) may be used for the test inoculum into a guinea-pig (Fig. 8), that is as a 'biopsy' from the person to be tested for ageing status. This opens up the possibility of studying systematically genetic and other influences on the ageing process in man and animals, and invites studies of the effects of diseases thought to 'age' people and also the 'immunological age assessment' of very old subjects reported in Ecuador and in Soviet Georgia. It may be mentioned that, while there is a strong genetic element in the development of natural scrapie in sheep (see above), there appear to be some examples at least of familial incidence of Jakob-Creutzfeldt disease, too. The famous Backer family contained 14 affected 
subjects in 4 generations (Kirschbaum, 1968; Jacob et al, 1950; Bonduelle et al, 1971) and a further example is the occurrence of the disease in 2 brothers and 1 sister (Davison and Rabiner, 1940).

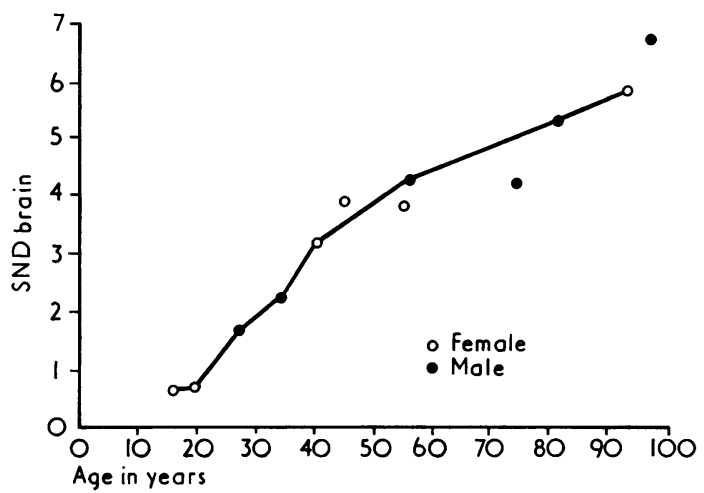

FIG. 8. Guinea-pig lymphocyte scrapie normal difference (SND) after injection with lymphocytes from humans of different ages. $\bullet=$ male, $O=$ female. (Courtesy of Gerontologia, 11, 211-219, 1973.)

The study can be extended to an analysis of the site of the new antigenic determinants. Are they limited to the plasma membrane (cell surface) as is the case with the neo-antigen of human malignant neoplasia (Dickinson et al, 1972) or do they affect endoplasmic reticulum and nuclear membrane too ? In the case of scrapie there is some evidence that all subcellular constituents contain scrapie activity. Is the development of a new surface conformation of cell membrane a contributory factor to impaired functioning as a unit of the collection of cells which constitutes an organ? And does this contribute to the ultimate dissolution called 'death'?

Finally, the problem has spread to involve the thymus gland. Since many features of 'runt' disease which overtakes a proportion of neonatally thymectomized mice and rats resemble a precocious ageing, tissues from such animals were tested for the development of scrapie-like antigens at intervals after operation. A startingly precocious development of scrapie-like antigen(s) occurred, as shown by the development of high scrapie-normal disease lymphocyte sensitization in guinea-pigs injected with tissues from these animals (Fig. 9). Sham operated animals 'aged' at the normal pace (Field and Shenton, 1973d). Moreover, implants of thymus from a 10-day-old mouse into neonatally thymectomized animals, held up the development of the scrapie-like ageing antigen(s) (Field and Shenton, 1973e). The magnitude of the effect produced by thymectomy was striking. Thus, 14 days after removal of the gland, the scrapie-normal difference evoked was greater than that produced by inoculation of tissues from a normal 203-day-old mouse; and a 48-day thymectomized animal gave a scrapienormal difference from both brain and spleen greater than that from a normal 840-day animal. The mechanism by which the thymus affects the development of scrapie-like antigens in tissues is unknown, though several writers (e.g. Fabris et al, 1972) have drawn attention to the relation between thymus cells and the ageing process.

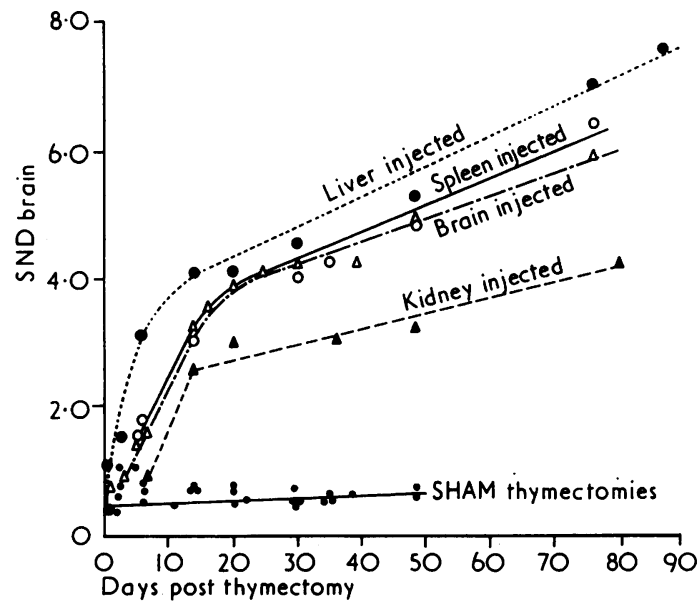

FIG. 9. Scrapie normal difference (SND) of lymphocytes of guineapig inoculated 8 days previously with tissues of a neonatally thymecte tomized mouse. (Courtesy of Gerontologia, 19, 211-219, 1973.)

It has been suggested that some of the changes in the ageing brain may result from activation of latent viruses with ageing (Gajdusek, 1971). However, the writer's view is that ageing changes in tissues are associated with physicochemical alterations in cellular membranes resulting in the appearance of antigenic determinants which also make their appearance in the tissues of young scrapie animals. Whether scrapie is, in fact, caused by an 'agent' remains to be determined, and prolonged search by many observers has not led to recognition of any particular agent in the tissues (cf. Narang and Field, 1972; Cho and Greig, 1975). For the writer, the presence of various viruses in ageing tissues may well represent their emergence from a latent 'integrated' state-perhaps within the host genome-when the milieu becomes less satisfactory ('aged'), rather than a causal relation with the changes of ageing. Finally, it may be speculated that maintenance of morphology while individual components are changing (as evidenced strikingly by radioactive tracer studies in many tissues over the past two decades) is at the core of the living process. If the accurate 
turnover process fails at some point (and with the passage of time it becomes more and more likely to happen), then this may serve as a point of constraint in Changeux's sense from which the process spreads. The deliberate introduction of such a seeding point is the artificial inoculation of 'scrapie agent'.

The author is indebted to Mr I. H. Pattison, A. R. C. Compton, for Fig. 1. Fig. 2 to 6 are reproduced by courtesy of Academic Press from Field (1969). Fig. 7 to 9 are reproduced by kind permission of Messrs. Karger, Basel, from already published work cited.

\section{REFERENCES}

Adams, D. H. and Caspary, E. A. (1967). Nature of the scrapie virus. British Medical fournal, 3, 173.

Adams, D. H. and Field, E. J. (1968). The infective process in scrapie. Lancet, 2, 714-716.

Alper, T., Cramp, N. A., Haig, D. A., and Clarke, M. C. (1967). Does the agent of scrapie replicate without nucleic acid? Nature (London), 214, 764-766.

Alper, T., Haig, D. A., and Clarke, M. C. (1966). The exceptionally small size of the scrapie agent. Biochemical and Biophysical Research Communications, 22, 278-284.

Beck, E. and Daniel, P. M. (1965). Kuru and scrapie compared: are they examples of system degeneration? In Slow, Latent, and Temperate Virus Infections, pp. 85-93. (NINDB Monograph No. 2.) Ed. by D. C. Gajdusek, C. J. Gibbs, Jr., and M. Alpers. U.S. Department of Health, Education and Welfare, Washington D.C.

Beck, E., Daniel, P. M., and Parry, H. B. (1964). Degeneration of the cerebellar and hypothalamo-neurohypophysical systems in sheep with scrapie; and its relationship to human system degenertions. Brain, 87, 153-176.

Bell, T. M., Field, E. J., and Joyce, G. (1972). Action of an alcoholic solution of iodine on the scrapie agent. Research in Veterinary Science, 13, 198-199.

Benfante, R. J., Traub, R. D., Lim, K. A., Hooks, J., Gibbs, C. J., Jr. and Gajdusek, D. C. (1974). Immunological reactions in kuru: attempts to demonstrate relationships between kuru and other known infectious agents. American fournal of Tropical Medicine and Hygiene, 23, 476-488.

Bennett, J. H., Rhodes, F. A., and Robson, H. N. (1958). Observations on Kuru: a possible genetic basis. Australasian Annals of Medicine, 7, 269-275.

Bennett, J. H., Rhodes, F. A., and Robson, H. N. (1959). A possible genetic basis for kuru. American fournal of Human Genetics, 11, 169-187.

Bloom, B. R. and Bennett, B. (1966). Mechanism of a reaction in vitro associated with delayed-type hypersensitivity. Science, $153,80-82$

Bonduelle, M., Escourolle, R., Bouygues, P., Lormeau, G., RibadeauDumas, J. R., and Meland, J. J. (1971). Maladie de CreutzfeldtJakob familiale; observation anatomo-clinique. Revue Neurologique, 125, 197-209.

Bosanquet, F. D., Daniel, P. M., and Parry, H. B. (1956). Myopathy in sheep. Its relationship to scrapie and to dermatomyositis and muscular dystrophy. Lancet, $2,737-746$.

Brown, P. and Gajdusek, D. C. (1974). No mouse P.M.N. leukocyte depression after inoculation with brain tissue from multiple sclerosis or spongiform encephalopathies. Nature (London), 247, 217-218.

Brownell, B., Campbell, M. J., Greenham, L. W., and Peacock, D. B. (1975). Experimental transmission of Jakob-Creutzfeldt disease. Lancet, 2, 186-187.

Bull, L. B. and Murnane, D. (1958). An outbreak of scrapie in British sheep imported into Victoria. Australian Veterinary fournal, 34, 213-215.

Burger, D. and Hartsough, G. R. (1965). Encephalopathy of Mink. II. Experimental and natural transmission. Fournal of Infectious Diseases, 115, 393-399.

Campbell, A. M. G., Daniel, P. M., Porter, R. J., Ritchie-Russell, W., Smith, H. V., and Innes, J. R. M. (1947). Diseases of the nervous system occurring amongst research workers on swayback in lambs. Brain, 70, 50-58.
Carnegie, P. R., Caspary, E. A., Dickinson, J. P., and Field, E. J. (1973). The macrophage electrophoretic migration (MEM) test for lymphocyte sensitization: a study of the kinetics. Clinical and Experimental Immunology, 14, 37-45.

Carp, R. I., Licursi, P. C., Merz, P. A., and Merz, G. S. (1972). Decreased percentage of polymorphonuclear neutrophils in mouse peripheral blood after inoculation with material from multiple sclerosis patients. Fournal of Experimental Medicine, 136, 618-629. Carp, R. I., Merz, P. A., Licursi, P. C., and Merz, G. S. (1973). Replication of the factor in scrapie material that causes a decrease in polymorphonuclear neutrophils. Fournal of Infectious Diseases, 128, 256-258.

Caspary, E. A. and Field, E. J. (1971). Specific lymphocyte sensitization in cancer; is there a common antigen in human malignant neoplasia? British Medical fournal, 2, 613-617.

Caspary, E. A. and Field, E. J. (1974). Lymphocyte sensitization to basic protein of brain in multiple sclerosis and other neurological diseases. Fournal of Neurology, Neurosurgery and Psychiatry, 37, 710-703.

Chandler, R. L. (1959). Attempts to demonstrate antibodies in scrapie disease. Veterinary Record, 71, 58 .

Chandler, R. L. (1961). Encephalopathy in mice produced by inoculation with scrapie brain material. Lancet, 1, 1378-1379.

Chandler, R. L. and Fisher, J. (1963). Experimental transmission of scrapie to rats. Lancet, $2,1165$.

Changeux, J. P. and Thiéry, J. (1967). On the mode of action of colicons: a model of regulation at the membrane level. Fournal of Theoretical Biology, 17, 315-318.

Changeux, J. P., Thiéry, J., Tung, Y., and Kittel, C. (1967). On the co-operativity of biological membranes. Proceedings of the National Academy of Sciences of the United States of America, 57, 335-341.

Charcot, J. M. (1872). De la sclérose en plaques disseminéesAnatomie pathologique. In Maladies du Système Nerveux, pp. 168-240. Delahaye, Paris.

Chelle, P. L. (1942). Un cas de tremblante chez la chèvre. Bulletin de l'Académie Vétérinaire de France, 15, 294-295.

Cho, H. J. and Greig, A. S. (1975). Isolation of $14 \mathrm{~nm}$ virus-like particles from mouse brain infected with scrapie agent. Nature (London), 257, 685-686.

Clarke, M. C. (1968). The antibody response of scrapie affected mice to immunization with sheep red blood cells. Research in Veterinary Science, 9, 595-597.

Clarke, M. C. and Haig, D. A. (1966). Attempts to demonstrate neutralizing antibodies in the sera of scrappie affected animals. Veterinary Record, 78, 647-649.

Clarke, M. C. and Haig, D. A. (1967). Presence of the transmissible agent of scrapie in the serum of affected mice and rats. Veterinary Record, 80, 504.

Clarke, M. C. and Haig, D. A. (1970). Multiplication of scrapie agent in cell culture. Research in Veterinary Science, 11, 501-502.

Cuille, J. and Chelle, P. L. (1936). La maladie dite tremblante du mouton est-elle inoculable? Comptes Rendus Hebdomadaires des Séances de l'Académe des Sciences, 203, 1552-1534.

David, J. R., Al-Askari, S., Lawrence, H. S., and Thomas, L. (1964). Delayed hypersensitivity in vitro. I. The specificity of inhibition of cell migration by antigens. Fournal of Immunology, 93, 264-273.

Davison, C. and Rabiner, A. M. (1940). Spastic pseudosclerosis. Archives of Neurology, 44, 573-583.

Dick, G. W. A., McAlister, J. J., Mackeown, F., and Campbell, A. M. G. (1965). Multiple sclerosis and scrapie. fournal of Neurology, Neurosurgery and Psychiatry, 28, 560-562.

Dickinson, A. G. (1971). Competition between different strains of scrapie agent and their interaction with the host genotype. Heredity, 27, 313-314.

Dickinson, A. G., Fraser, H., and Outram, G. N. (1975). Scrapie incubation time can exceed natural lifespan. Nature (London), 256, 732-733.

Dickinson, A. G. and Meikle, V. M. H. (1969). A comparison of some biological characteristics of the mouse passaged scrapie agents 22A and ME7. Genetical Research, 13, 213-225.

Dickinson, A. G., Meikle, V. M. H., and Fraser, H. (1968a). Identification of a gene which controls the incubation period of some strains of scrapie agent in mice. Fournal of Comparative Pathology and Therapeutics, 78, 293-299.

Dickinson, A. G., Meikle, V. M. H., and Fraser, H. (1969). Genetical control of the concentration of ME7 scrapie agent in the brain of mice. Fournal of Comparative Pathology and Therapeutics, 79, 15-22. 
Dickinson, A. G., Stamp, J. T., Renwick, C. C., and Rennie, J. C. (1968b). Some factors controlling the incidence of scrapie in cheviot sheep injected with a cheviot-passaged scrapie agent. Fournal of Comparative Pathology and Therapeutics, 78, 313-321.

Dickinson, A. G., Taylor, D. M., and Fraser, H. (1974). Depression of polymorph counts by various scrapie agents. Nature (London), 248, 510-511.

Dickinson, J. P., Caspary, E. A., and Field, E. J. (1972). Localization of tumour specific antigen on external surface of plasma membrane. Nature New Biology, 239, 181-183.

Diener, T. O. (1971). Potato spindle tuber virus: a plant virus with properties of a free nucleic acid: 3. subcellular location of PSTVRNA and the question of whether virions exist in extracts or in situ. Virology, 43, 75-89.

Diener, T. O. (1972). Is the scrapie agent a viroid. Nature New Biology, 235, 218-219.

Diener, T. O. (1974). Viroids: the smallest known agents of infectious disease. Annual Review of Microbiology, 28, 23-39.

Diener, T. O. and Raymer, W. B. (1967). Potato spindle tuber virus: a plant virus with properties of a free nucleic acid. Science, 158, 378-381.

Eckroade, R. J., Zurhein, G. M., Marsh, R. F., and Hanson, R. P. (1970). Transmissible mink enencephalopathy: experimental transmission to the squirrel monkey. Science, 169, 1088-1090.

Eklund, C. M., Kennedy, R. C., and Hadlow, W. J. (1965). Pathogenesis of scrapie infection in the mouse. In Slow, Latent and Temperate Virus Infections (NINDB Monograph No. 2.) Ed. by D. C. Gajdusek, C. J. Gibbs, Jr., and M. Alpers. U.S. Department of Health, Education and Welfare, Washington D.C.

Eklund, C. M., Kennedy, R. C., and Hadlow, W. J. (1967). Pathogenesis of scrapie virus infection in the mouse. Fournal of Infectious Diseases, 117, 15-22.

Fabris, N., Pierpaoli, W., and Sorkin, E. (1972). Lymphocytes, hormones, and ageing. 'Nature (London), 240, 557-559.

Field, E. J. (1966). Transmission experiments with multiple sclerosis: an interim report. British Medical fournal, 2, 564-565.

Field, E. J. (1967a). Invasion of the mouse nervous system by scrapie agent. British fournal of Experimental Pathology, 48, 662-664.

Field, E. J. (1967b). The significance of astroglial hypertrophy in scrapie, kuru, multiple sclerosis and old age, together with a note on the possible nature of the scrapie agent. Deutsche Zeitschrift für Nervenheilkunde, 192, 265-274.

Field, E. J. (1967c). Transmission of kuru to mice. Lancet, 1, 981-982.

Field, E. J. (1969). Slow virus infections of the nervous system. International Review of Experimental Pathology, 8, 130-239.

Field, E. J. (1975). Multiple sclerosis: relation to scrapie and slow infection: ageing and measles. Acta Neurologica Scandinavica, 51, 285-298.

Field, E. J. and Caspary, E. A. (1970). Lymphocyte sensitization: an in vitro test for cancer. Lancet, 2, 1137-1141.

Field, E. J., Caspary, E. A., and Joyce, G. (1968). Scrapie agent in blood. Veterinary Record, 83, 109-110.

Field, E. J., Caspary, E. A., and Windsor, G. D. (1966). Sodium and potassium in scrapie brain. Research in Veterinary Sciences, 7, 72-73.

Field, E. J., Farmer, F., Caspary, E. A., and Joyce, G. (1969). Susceptibility of scrapie agent to ionizing radiation. Nature (London), 222, 90-91.

Field, E. J. and Joyce, G. (1970). Evidence against transmission of scrapie by animal house formites. Nature (London), 226, 971-973.

Field, E. J., Joyce, G., and Keith, A. (1971). Viral properties of scrapie. Nature New Biology, 230, 56-57.

Field, E. J. and Raine, C. S. (1964). An electron microscopic study of scrapie in the mouse. Acta Neuropathologica, 4, 200-211.

Field, E. J. and Shenton, B. K. (1972). Rapid diagnosis of scrapie in the mouse. Nature (London), 240, 104-105.

Field, E. J. and Shenton, B. K. (1973a). Altered response to scrapie tissues in neurological disease: possible evidence for an antigen associated with reactive astrocytes. Brain, 96, 629-636.

Field, E. J. and Shenton, B. K. (1973b). Immunological reactions in scrapie: the basis of a rapid titration method. Path. Biol., 21, 1051-1056.

Field, E. J. and Shenton, B. K. (1973c). Emergence of new antigens in ageing tissues. Gerontologia, 19, 211-219.

Field, E. J. and Shenton, B. K. (1973d). Thymectomy and immunological ageing in mice: precocious emergence of scrapie-like antigen. Gerontologia, 19, 203-210.
Field, E. J. and Shenton, B. K. (1973e). Retardation of 'ageing' (presence of scrapie-like antigens) in mice by implants of thymus tissue. I.R.C.S. (73-6) 5-10-3.

Field, E. J. and Shenton, B. K. (1974). A rapid immunologic test for scrapie in the sheep. American fournal of Veterinary $R e-$ search, 35, 393-395.

Field, E. J. and Shenton, B. K. (1975). Cellular sensitization in kuru, Jakob-Creutzfeldt disease and multiple sclerosis with a note on the biohazards of slow infection work. Acta Neurologica Scandinavica, 51, 299-309.

Field, E. J., Shenton, B. K., and Joyce, G. (1974a). Specific laboratory test for diagnosis of multiple sclerosis. British Medical fournal, 1, 412-414.

Field, E. J., Shenton, B. K., Joyce, G., and Buntain, D. (1974b). Multiple sclerosis and scrapie. I.R.C.S., 2, 1041

Field, E. J. and Windsor, G. D. (1965). Cultural characters of scrapie mouse brain. Research in Veterinary Science, 6, 130-132.

Fitzsimmons, W. M. and Pattison, I. H. (1968). Unsuccessful attempts to transmit scrapie by nematode parasites. Research in Veterinary Science, 9, 281-283.

Fraser, H. and Bruce, M. (1973). Angyrophilic plaques in mice inoculated with scrapie from particular sources. Lancet, 1, 617.

Fuccillo, D. A., Kurent, J. E., and Sever, J. L. (1974). Slow virus disease. Annual Review of Microbiology, 28, 231-264.

Gajdusek, D. C. (1971). Slow virus diseases of the central nervous system. American fournal of Clinical Pathology, 56, 320-326.

Gajdusek, D. C. and Gibbs, C. J., Jr. (1968). Slow, latent and temperate virus infections of the central nervous system. In 'Infections of the Nervous System'. Association for Research in Nervous and Mental Disease, 44, 254-280.

Gajdusek, D. C., Gibbs, C. J., and Alpers, M. (1965). (Eds.) Slow, Latent and Temperate Virus Infections. (NINDB Monograph No. 2.) U.S. Department of Health, Education, and Welfare, Washington D.C.

Gajdusek, D. C., Gibbs, C. J., Jr., and Alpers, M. (1966). Experimental transmission of a kuru-like syndrome to chimpanzees. Nature (London), 209, 794-796.

Gajdusek, D. C., Gibbs, C. J., Jr., and Alpers, M. (1967). Transmission and passage of experimental 'kuru' to chimpanzees. Science, 155, 212-214.

Gajdusek, D. C., Gibbs, C. J., Jr., Asher, D. M., and David, E. (1968). Transmission of experimental kuru to the spider monkey. Science, 162, 693-694.

Gardiner, A. C. (1965). Gel diffusion reactions of tissues and sera from scrapie affected animals. Research in Veterinary Science, 7,' 190-195.

Gardiner, A. C. and Marucci, A. A. (1969). Immunological responsiveness of scrapie infected mice. Fournal of Comparative Pathology, 79, 233-235.

Gibbons, R. A. and Hunter, G. D. (1967). Nature of the scrapie agent. Nature (London), 215, 1041-1043.

Gibbs, C. J., Jr. and Gajdusek, D. C. (1971). Transmission and characterization of the agents of spongiform-virus encephalopathies: kuru, Creutzfeldt-Jakob disease, scrapie and mink encephalopathy. In Immunological Disorders of the Nervous System. Ed. by L. R. Rowland. Ass. Res. Nerv. Ment. Dis., 49, 383. Williams and Wilkins, Baltimore.

Gibbs, C. J., Jr. and Gajdusek, D. C. (1972). Transmission of scrapie to the cynomolgus monkey (Macaca fascicularis). Nature (London), 236, 73-74.

Gibbs, C. J., Jr. and Gajdusek, D. C. (1973). Experimental subacute spongiform virus encephalopathies in primates and other laboratory animals. Science, 182, 67-68.

Gibbs, C. J., Jr., Gajdusek, D. C., Asher, D. M., Alpers, M., Beck, E., Daniel, P. M., and Matthews, W. B. (1968). CreutzfeldtJakob disease (spongiform encephalopathy): transmission to the chimpanzee. Science, 161, 388-389.

Goldstone, A. H., Kerr, L., and Irvine, W. J. (1973). The macrophage electrophoretic migration test in cancer. Clinical and Experimental Immunology, 14, 469-472.

Gordon, W. S. (1966a). Agric. Res. Counc. Report of Scrapie Seminar, held at Washington D.C., 27-30 January 1964, pp. 19-36

Gordon, W. S. (1966b). Agric. Res. Counc. 'Report of Scrapie Seminar held at Washington D.C., 27-30 January 1964', pp. 8-13.

Gustafson, D. P. and Kanitz, C. L. (1965). Evidence for the presence of scrapie in cell cultures of brain. In Slow, Latent and Temperate Virus Infections, pp. 221-236. (NINDB Monograph 
2.) Ed. by D. C. Gajdusek, C. J. Gibbs, Jr., and M. Alpers. U.S. Department of Health, Education and Welfare, Washington D.C. Hadlow, W. J. (1959). Scrapie and kuru. Lancet, 2, 289-290.

Hadlow, W. J. (1961). The pathology of experimental scrapie in the dairy goat. Research in Veterinary Science, 2, 289-314.

Haig, D. A. and Pattison, I. H. (1967). In vitro growth of pieces of brain from scrapie affected mice. Fournal of Pathology and Bacteriology, 93, 724-727.

Hartsough, G. R. and Burger, D. (1965). Encephalopathy in mink. I. Epizoological and clinical observations. Fournal of Infectious Diseases, 115, 387-392.

Hulland, T. J. (1958). The skeletal muscle of sheep affected with scrapie. Fournal of Comparative Pathology and Therapeutics, 68, 264-274.

Hunter, G. D. (1974). Scrapie. Progress in Medical Virology, 18, 289-306.

Hunter, G. D., Kimberlin, R. H., and Gibbons, R. A. (1968). Scrapie: a modified membrane hypothesis. fournal of Theoretical Biology, 20, 355-357.

Jacob, H., Pyrkosch, W., and Strube, H. (1950). Die erbliche, Form der Creutzfeldt-Jakobschen Krankheit. Archiv für Psychiatrie und Nervenkrankheiten, 184, 653-667.

Jenssen, H. L., Kohler, H., Gunther, J., and Meyer-Rienecker, H. J. (1974). Specific test for multiple sclerosis. Lancet, 2, 1327.

Jenssen, H. L., Meyer-Rienecker, H. J., Kohler, H., and Gunther, J. K. (1975). The linoleic acid depression (LAD) test for multiple sclerosis using the macrophage electrophoretic mobility (MEM) test. Acta Neurologica Scandinavica, 53, 51-60.

Kakulas, B. A., Lecours, A. R., and Gajdusek, D. C. (1967). Further observations on the pathology of kuru. Fournal of Neuropathology and Experimental Neurology, 20, 85-97.

Kimberlin, R. H., Millson, G. C., and Hunter, G. D. (1971). An experimental examination of the scrapie agent in cell membrane mixtures. III. Studies of the operational size. Fournal of Comparative Pathology, 81, 383-391.

Kirschbaum, W. R. (1968). Fakob-Creutzfeldt Disease. American Elsevier, New York.

Lancet (1967). Leading article: The Scrapie agent. 2, 705-706.

Lewkonia, R. M., Kerr, E. J. L., and Irvine, W. J. (1974). Clinical evaluation of the macrophage electrophoretic mobility test for cancer. British fournal of Cancer, 30, 532-537.

Licursi, P. C., Merz, P. A., Merz, G. S., and Carp, R. I. (1972). Scrapie induced changes in the percentage of polymorphonuclear neutrophils in mouse peripheral blood. Inf. Immun., 6, 370-376.

McDermott, R. J., Field, E. J., and Caspary, E. A. (1974). Relation of measles virus to encephalitogenic factor with reference to the aetiopathogenesis of multiple sclerosis. Fournal of Neurology, Neurosurgery, and Psychiatry, 37, 282-287.

McGowan, J. P. (1914). Investigations into the Disease of Sheep called Scrapie, with Special Reference to its Association with Sarcospoidiosis. Blackwood, Edinburgh.

Marsh, R.F., Burger, D., Eckroade, R., Zurhein, G. M., and Hanson, R. P. (1969). A preliminary report on the experimental host range of the transmissible mink encephalopathy agent. Fournal of Infectious Diseases, 120, 713-719.

Marsh, R. F. and Hanson, R. P. (1969). Transmissible mink encephalopathy. American fournal of Veterinary Research, 30, 16431653.

Meyer-Rienecker, H., Jenssen, H. L., Köhler, H., Gunther, J., and Gundlach, H. J. (1974). Zur Anwendung und Bedeutung des Makrophagen-Elektrophorese-Mobilitäts- (MEM) -Testes bei Neurologischen Erkrankungen. Klinische Wochenschrift, 52, 288-292.

M'Fadyean, J. (1918). Scrapie. Fournal of Comparative Pathology and Therapeutics, 31, 102-131.

Morris, J. A., Gajdusek, D. C., and Gibbs, C. J., Jr. (1966). Spread of scrapie from inoculated to uninoculated mice. Proceedings of the Society for Experimental Biology, and Medicine, 120, 108-110.

Narang, H. K. and Field, E. J. (1972). An electron microscopic study of scrapie in the rat: further observations on inclusion bodies and virus like particles. Fournal of the Neurological Sciences, 17, 347-364.

Nussbaum, R. E., Henderson, M., Pattison, I. H., Elcock, N. V., and Davis, D. C. (1975). The establishment of sheep flocks of predictable susceptibility to experimental scrapie. Research in Veterinary Science, 18, 49-58.

Palmer, A. G. (1959). Scrapie: a review of the literature. Veterinary Reviews and Annotations, 5, 1-15.

Palsson, P. A., Pattison, I. H., and Field, E. J. (1965). Transmission experiments with multiple sclerosis. In Slow, Latent, and Temperate Virus Infections, pp. 49-54. (NINDB monograph No. 2.) Ed. by D. C. Gajdusek, C. J. Gibbs, Jr., and M. Alpers. U.S. Department of Health, Education, and Welfare, Washington D.C.

Parry, H. B. (1962). A transmissible and hereditary disease of sheep Heredity, 17, 75-105.

Pattison, I. H. (1957). Myopathy in sheep. Lancet, 1, 104-105.

Pattison, I. H. (1965). Experiments with scrapie with special reference to the nature of the agent and the pathology of the disease. In Slow, Latent, and Temperate Virus Infections, pp. 249-257. (NINDB monograph No. 2.) Ed. by D. C. Gajdusek, C. J. Gibbs, Jr., and M. Alpers. U.S. Department of Health, Education and Welfare, Washington D.C.

Pattison, I. H., Hoare, M. N., Jebbett, J. N., and Watson, W. A. (1972). Spread of scrapie to sheep and goats by oral dosing with foetal membranes from scrapie affected sheep. Veterinary Record, 90, 465-468.

Pattison, I. H. and Jebbett, J. N. (1971). Clinical and histological observations on cuprizone toxicity and scrapie in mice. Research in Veterinary Science, 12, 378-380.

Pattison, I. H. and Jones, K. M. (1967). The possible nature of the transmissible agent of scrapie. Veterinary Record, 80, 2-9.

Pattison, I. H. and Jones, K. M. (1968a). Modification of a strain of mouse adapted scrapie by passage through rats. Research in Veterinary Science, 9, 408-410.

Pattison, I. H. and Jones, K. M. (1968b). Detection of the scrapie agent in tissues of normal mice and in tumours of tumour-bearing but otherwise normal mice. Nature (London), 218, 102-104.

Pattison, I. H., Millson, G. C., and Smith, K. (1964). An examination of the action of the whole blood, blood cells or serum on the goat scrapie agent. Research in Veterinary Science, 5, 116-121.

Pirie, N. W. (1966). Biological organization of viruses. In Principles of Biomolecular Organization. Ciba Foundation Symposium, pp. 136-152; and Discussion, pp. 152-154. Ed. by G. E. W. Wolstenholme and M. O'Connor. Churchill, London.

Preece, A. W. and Light, P. A. (1974). The macrophage electrophoretic mobility (MEM) test for malignant disease. Clinical and Experimental Immunology, 18, 543-552.

Pritchard, J. A. V., Moore, J. L., Sutherland, W. H., and Joslin, C. A. F. (1972). Macrophage electrophoretic mobility (MEM) test for malignant disease: an independent confirmation. Lancet, $2,627-629$

Pritchard, J. A. V., Moore, J. L., Sutherland, W. H., and Joslin, C. A. F. (1973). Evaluation and development of the macrophage electrophoretic mobility (MEM) test for malignant disease. British fournal of Cancer, 27, $1-9$.

Savage, R. D. and Field, E. J. (1965). Brain damage and emotional behaviour: the effects of scrapie on the emotional responses of mice. Animal Behaviour, 13, 443-446.

Schapira, K., Poskanzer, D. C., and Miller, H. (1963). Familial and conjugal multiple sclerosis. Brain, 86, 315-332.

Shenton, B. K. and Field, E. J. (1975). Macrophage electrophoretic mobility (MEM) test: some technical considerations. Fournal of Immunological Methods, 7, 149-162.

Shenton, B. K., Hughes, D., and Field, E. J. (1973). Macrophage electrophoretic migration (MEM) test for lymphocyte sensitization: some practical experiences in macrophage selection. British fournal of Cancer, 28, Suppl. I, 215-218.

Sigurdsson, B. (1954). Observations on three slow infections of sheep. British Veterinary fournal, 110, 255-270, 307-322, and 341-354.

Stamp, J. T. (1956). The enigma of scrapie disease in sheep. Agric. Rev. (London), 2, 18-20.

Stamp, J. T. (1967). Scrapie and its wider implications. British Medical Bulletin, 23, 133-137.

Stockman, S. (1913). Scrapie, an obscure disease of sheep. fournal of Comparative Pathology and Therapeutics, 26, 317-327.

Stockman, S. (1926). Contribution to the study of the disease known as scrapie. Fournal of Comparative Pathology and Therapeutics, 39, 42-71.

Sutherland, J. M. and Wilson, D. R. (1951). Disseminated sclerosis in man and experimentation with sheep. Glasgow Medical fournal, 32, 302-310.

Wilson, D. R., Anderson, R. D., and Smith, W. (1950). Studies in scrapie. Fournal of Comparative Pathology and Therapeutics, 62 , 267-282.

Zlotnik, I. and Katiyar, R. D. (1961). The occurrence of scrapie disease in sheep of the remote Himalayan foothills. Veterinary Record, 73, 543-544. 